\title{
Erratum to: Inbreeding Affects Locomotor Activity in Drosophila melanogaster at Different Ages
}

\author{
Tommaso Manenti - Cino Pertoldi • Neda Nasiri Moghadam • \\ Mads Fristrup Schou • Anders Kjærsgaard • \\ Sandro Cavicchi $\cdot$ Volker Loeschcke
}

Published online: 18 October 2014

(C) Springer Science+Business Media New York 2014

\section{Erratum to: Behav Genet}

DOI: 10.1007/s10519-014-9683-5

Unfortunately, the name of third author (Neda Nasiri Moghadam) was incorrect in the original publication. The author's name is corrected with this erratum.

The online version of the original article can be found under doi:10.1007/s10519-014-9683-5.

T. Manenti $(\bowtie) \cdot$ C. Pertoldi · N. N. Moghadam .

M. F. Schou - A. Kjærsgaard · S. Cavicchi · V. Loeschcke Department of Bioscience, Genetics, Ecology and Evolution, Aarhus University, Ny Munkegade 114-116, Buildg. 1540, 8000 Aarhus C, Denmark

e-mail: tommaso@biology.au.dk

C. Pertoldi

Department of Biotechnology, Chemistry and Environmental Engineering - Section of Biology and Environmental Science, Aalborg University, Sohngårdsholmsvej 57, 9000 Aalborg,

Denmark

C. Pertoldi

Aalborg Zoo, Aalborg, Denmark

A. Kjærsgaard

Institute of Evolutionary Biology and Environmental Studies, University of Zurich, Winterthurerstrasse 190, 8057 Zurich,

Switzerland 